Article

\title{
Evaluation of Mugwort (Artemisia vulgaris L.) Aqueous Extract as a Potential Bioherbicide to Control Amaranthus retroflexus L. in Maize
}

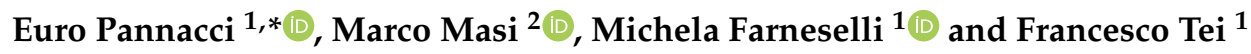 \\ 1 Department of Agricultural, Food and Environmental Sciences, University of Perugia, Borgo XX Giugno, \\ 74-06121 Perugia, Italy; michela.farneselli@unipg.it (M.F.); francesco.tei@unipg.it (F.T.) \\ 2 Department of Chemical Sciences, University of Naples Federico II, \\ Complesso Universitario Monte S. Angelo, 80126 Naples, Italy; marco.masi@unina.it \\ * Correspondence: euro.pannacci@unipg.it
}

Received: 23 November 2020; Accepted: 15 December 2020; Published: 17 December 2020

\begin{abstract}
The allelopathic plant extracts can be applied as soil or foliar bioherbicides and are capable of suppressing germination and growth of several weeds, some of which are herbicide resistant. This study evaluated the allelopathic activity of the aqueous extract of aerial biomass of mugwort (Artemisia vulgaris L.) on seed germination and seedling growth of redroot pigweed (Amaranthus retroflexus L.) and maize (Zea mays L.), in order to be applied as a potential bioherbicide. The aqueous extract of mugwort was qualitatively examined for the presence of bioactive compounds and it was applied in a Petri dish and pot bioassays quantifying its effects on redroot pigweed and maize by non-linear regression analyses according the log-logistic model. The aqueous extract of mugwort showed the presence of several bioactive compounds with allelopathic activity, such as polysaccharides, organic acids, flavonoids and terpenoids. The aqueous extract of mugwort, at the concentrations from $7.5 \%$ to $10 \% w / v$, were found to be the optimal concentration range since it is able to inhibit seed germination, seedling emergence and plant growth of redroot pigweed, without affecting seed germination and seedling emergence of maize, or rather, stimulating its radicle, mesocotyl and plant's growth. $\mathrm{EC}_{90}$ values for the seed germination, radicle and hypocotyl length of redroot pigweed were in the order: $6.1 \%$ and $8.1 \%, 3.2 \%$ and $6.2 \%, 3.8 \%$ and $5.7 \% w / v$ of aqueous extract in the two repeated bioassays, respectively. Due to potential herbicidal activity against weeds and biostimulant action on the crops, this extract could be the ideal solution in an integrated weed management program, in order to suppress weeds, increasing competitive ability of crops.
\end{abstract}

Keywords: redroot pigweed; Zea mays L.; allelopathy; integrated weed management (IWM); natural herbicide; biostimulants

\section{Introduction}

Maize (Zea mays L.) is one of the world's three major cereal crops, ranking second in importance after wheat and before rice as area harvested, and first in importance as yield production, in 2018 [1]. The world production of maize was estimated at 1.05 million thousand tons in 2019 and it is considered as a staple food in many parts of the world: the largest producer of maize is the United States of America (USA) contributing about $33 \%$ of the total world maize production [2]. In Southern and Eastern Africa, it is the main source of food and agricultural income for smallholder farmers [3]; while within the 28 Member States of the European Union (EU) the production in 2019 reached 70 million tons mainly used for animal feed ( $80 \%)$ and secondarily for industry $(13 \%)$ and humans $(7 \%)$ [4]. Maize is a source of nutrition as well as phytochemical compounds (carotenoids, phenolic compounds, phytosterols) 
that play an important role in preventing chronic diseases and it is believed to have potential anti-HIV activity due to the presence of Galanthus nivalis agglutinin (GNA) lectin or GNA-maize [5]. It is widely processed into various types of products such as cornmeal, grits, starch, flour, tortillas, snacks and breakfast cereals.

Weeds regularly cause important maize crop losses that can reached $90 \%$ in the developing countries, such as Africa [3]. Therefore, weed control has a major effect on the success of maize growth, because the competition ability of maize is relatively low, especially at early crop growth stages [6]. In fact, in more developed parts of the world, which are characterized by higher agricultural inputs, farmers rely heavily on the use of herbicides to control weeds; more than $90 \%$ of the maize production area in all European regions is manage with herbicides [7].

However, environmental and human health impact of herbicides use, increasing of herbicide resistance and organic farming were the main factors that stimulated the interest to develop weed control methods alternative to chemical control [8-11]. Allelopathy, defined as all direct positive or negative effects of a plant on another plant or on micro-organisms by the liberation of biochemicals into the natural environment, could be used as a weed control tool in order to reduce the use of herbicides and improve weed management strategies, both in the integrated and organic farming systems [12-15]. Combining the pre-emergence inoculation with the fungal pathogen Pyrenophora semeniperda and post-emergence imazapic application limits the spread of cheatgrass (Bromus tectorum L.) [16]. In two field experiments in winter wheat (Triticum aestivum L.), the mugwort (Artemisia vulgaris L.) aqueous extract $(20 \% w / v)$ in mixture with chlorsulfuron in a pre-emergence application, allowed to reduced up to $80 \%$ the dose of the herbicide, maintaining an effectiveness of $70 \%$ against Lolium multiflorum Lam. [17]. Interesting results were obtained by selecting allelopathic crop types, using allelopathic cover crops or phytotoxic extracts from crop residues [18]. A description of the latest updates of allelopathy for weed control and its possible integration to an IWM strategy for herbaceous field crops were reported by Scavo and Mauromicale [19]. Furthermore, recently, it was be noted an increased interest in studying allelopathic plant extracts as bioherbicides, with a particular attention on the allelopathic potentiality of weeds [20,21]. Many weeds are now achieving importance as agents of weed control, due to the production of allelochemicals, defined as secondary metabolites belonging to different chemical classes with inhibitory effects on target organisms [22]. The genus Artemisia (Asteraceae), consisting of over 200 species of herbs and shrubs, is well known for its wide spectrum of biological activities, including medicinal ones, due to the presence of volatile oils [23]. A. vulgaris (mugwort) is a rhizomatous perennial weed that commonly infests roadsides, waste areas and crop fields [24]. A remarkable number of secondary metabolites have been isolated from mugwort tissue and many of these being terpenes [24]. The rhizomes contain large quantities of 1,8-cineole, ascorbic acid, quercetin and vulgarin, a sesquiterpene lactone [25]. Mugwort exhibits strong allelopathic properties, either by foliar-produced or living rhizome-exudated phytotoxins, inhibiting the growth of several weeds and crops $[17,26,27]$. The allelopathic effects of the fresh leaves could not be reproduced with individual volatile isolates (monoterpenes), suggesting that toxicity results from a combination of monoterpenes [28].

Recently, Harker and O'Donovan [29] stressed as "given herbicide-resistant weed issue and consistent public pressure to reduce overall pesticide use, herbicide alternatives and true integrated weed management (IWM) strategies are urgently required now more than ever".

Redroot pigweed (Amaranthus retroflexus L.) is a common C4 weed in many agricultural areas and is reported to have a negative influence on several crops, such as sugar beet (Beta vulgaris L.), soybean (Glycine max L.), potato (Solanum tuberosum L.), cotton (Gossypium hirsutum L.) and maize (Z. mays L.) [30]. The maize yield loss due to redroot pigweed competition was reported to be from $5-34 \%$ [31] and $\leq 50 \%$ [32], depending on the redroot pigweed density. The intense use of certain herbicides led to the development of resistant populations of this weed worldwide. This resistance in redroot pigweed has evolved mainly due to herbicides in the Groups C1/5 (Photosystem II inhibitors) and B/2 (ALS inhibitors) [33]. Although mechanical and physical weed control methods are available to control redroot pigweed and other weeds in organic maize $[10,34]$, the development 
of bioherbicides, defined as products of natural origin for weed control, needs to be enhanced [35]. Recently, Masi et al. [36] isolated two new phytotoxic copaane sesquiterpenoids, named stoechanones A and B, from the organic extract of Lavandula stoechas L. that showed phytotoxic effects against seed germination and seedling growth of redroot pigweed.

The allelopathic plant extracts can be applied as soil or foliar bioherbicides and are capable of suppressing germination and growth of several weeds, some of which are herbicide resistant $[17,22]$.

Some studies were carried out on the allelopathic effects of mugwort against weeds and crops under laboratory, greenhouse and field conditions [37-39]; however, the allelopathic activity of mugwort against redroot pigweed and maize were not yet investigated.

The aim of this study was to evaluate the allelopathic activity of the aqueous extract of aerial biomass of mugwort on seed germination and seedling growth of redroot pigweed and maize in order to be applied as a potential bioherbicide.

\section{Materials and Methods}

\subsection{Plant Sampling and Extractions}

Plants of mugwort were collected from an uncultivated field in Marsciano, Perugia, central Italy $\left(42^{\circ} 56^{\prime} \mathrm{N}, 12^{\circ} 23^{\prime} \mathrm{E}, 165 \mathrm{~m}\right.$ a.s.l.) at the growth stage of $61-62 \mathrm{BBCH}$ scale (beginning of flowering: $10-20 \%$ of flowers open) [40]. Fresh mugwort plants were dried in a hot-air oven at $45^{\circ} \mathrm{C}$ for 5 days, and aerial biomass (leaves + stems) was ground with an electrical grinder, sieved through a $1 \mathrm{~mm}$ sieve, and kept in a dry and dark bag at $10{ }^{\circ} \mathrm{C}$ for future use. In laboratory, aerial biomass at $25 \mathrm{~g}$ dry tissue was soaked in $100 \mathrm{~mL}$ of distilled water $(25 \% \mathrm{w} / \mathrm{v})$ for $24 \mathrm{~h}$ at $24^{\circ} \mathrm{C}$. After soaking, the aqueous solution was filtered through 4-layers of cheesecloth to remove the fibre debris and then the aqueous extract was filtered again through filter paper. The resulting filtrate (used as stock extract in the following experiments) was frozen at $-20^{\circ} \mathrm{C}$ until extraction and analysis.

An aliquot of the aqueous stock extract $(5 \mathrm{~mL})$ was lyophilized yielding a residue of $127.2 \mathrm{mg}$. $10 \mathrm{mg}$ of this residue were dissolved in $\mathrm{D}_{2} \mathrm{O}$ and filtered on $0.2 \mu \mathrm{m}$ filters to record an ${ }^{1} \mathrm{H}-\mathrm{NMR}$ (proton nuclear magnetic resonance) spectrum of the hydrophilic compounds.

An aliquot of the aqueous stock extract $(2 \mathrm{~mL})$ was dialyzed in tubes with exclusion limits of $3500 \mathrm{Da}$. The dialysis was conducted in a discontinuous manner against large volumes of Milli-Q water and the contents of the dialysis tubing was lyophilized to give a residue of $32.1 \mathrm{mg}$. Then, $10 \mathrm{mg}$ of this residue were dissolved in $\mathrm{D}_{2} \mathrm{O}$ and filtered on $0.2 \mu \mathrm{m}$ filters to record an ${ }^{1} \mathrm{H}$-NMR spectrum of the high (>3500 Da) molecular weight compounds.

An aliquot of the aqueous stock extract $(40 \mathrm{~mL})$ was extracted in sequence with $n$-hexane, $\mathrm{CH}_{2} \mathrm{Cl}_{2}$, EtOAc and $n$-butanol (three times with $40 \mathrm{~mL}$ of each solvent). The combined organic extracts, obtained using the same solvent, were dried with $\mathrm{Na}_{2} \mathrm{SO}_{4}$ and evaporated under reduced pressure yielding 1.7, 17.2, 23.5 and $20.3 \mathrm{mg}$ of organic extracts as oily residues, respectively. These samples were checked by ${ }^{1} \mathrm{H}-\mathrm{NMR}$ and their chromatographic profiles were compared on TLC (Thin Layer Chromatography) using two different solvent systems $\left(\mathrm{CH}_{3} \mathrm{Cl}-i-\mathrm{PrOH}\right.$ 9:1 $v / v$ and EtOAc-MeOH- $\mathrm{H}_{2} \mathrm{O}$ 8.5:1.5:1.0 v/v/v). Solvents with increasing polarity were used in sequence to fractionate the low molecular weight compounds present in the aqueous stock extract.

An aliquot of the aqueous stock extract $(40 \mathrm{~mL}, \mathrm{pH}=7)$ was acidified with formic acid at $\mathrm{pH}=2$ and extracted with EtOAc (three times with $40 \mathrm{~mL}$ ) to obtain the low molecular weight organic acids. The combined organic extracts were dried with $\mathrm{Na}_{2} \mathrm{SO}_{4}$ and evaporated under reduced pressure yielding $147.9 \mathrm{mg}$ as a brown oily residue which was checked by TLC and ${ }^{1} \mathrm{H}-\mathrm{NMR}$.

\subsection{Extracts Chemical Characterization}

${ }^{1} \mathrm{H}-\mathrm{NMR}$ spectra were recorded at $400 \mathrm{MHz}$ in $\mathrm{D}_{2} \mathrm{O}, \mathrm{CDCl}_{3}$ and $\mathrm{CD}_{3} \mathrm{OD}$ on a Bruker (Billerica, MA, USA) spectrometer. The same solvent was used as internal standard. Analytical TLC were performed on silica gel (Kieselgel 60, F254, $0.25 \mathrm{~mm}$ ) plates (Merck, Darmstadt, Germany). The 
spots were visualized by exposure to UV radiation $(253 \mathrm{~nm})$, or iodine vapor, or by spraying first with $10 \% \mathrm{H}_{2} \mathrm{SO}_{4}$ in $\mathrm{MeOH}$ and then with $5 \%$ phosphomolybdic acid in $\mathrm{EtOH}$, followed by heating at $110^{\circ} \mathrm{C}$ for $10 \mathrm{~min}$. Sigma-Aldrich Co. (St. Louis, MO, USA) supplied all of the reagents and the solvents.

\subsection{Experiment 1: Petri Dish Bioassays}

Petri dish bioassays were carried out according to the methodology already showed by Pannacci et al. [17,18,41]. Seeds of maize (Z. mays subsp. Indurata, "flint corn", cv. 65b) and redroot pigweed were pre-sterilized with $2 \%$ sodium hypochlorite for $5 \mathrm{~min}$ and washed with distilled water. Fifty seeds of redroot pigweed were evenly placed on filter paper in sterilized separate 120-mm Petri dishes; while thirty seeds of maize were evenly placed on $150 \mathrm{~g}$ of quartz sand (inert substrate, $0.2-2 \mathrm{~mm}$ mesh size, $1.24 \mathrm{~g} \mathrm{~mL}^{-1}$ bulk density and $38.5 \mathrm{~mL} 100 \mathrm{~mL}^{-1}$ maximum water holding capacity) in sterilized separate 150-mm Petri dishes and then covered adding another $50 \mathrm{~g}$ of quartz sand. Stock extract of aerial biomass was diluted with distilled water to prepare $0,2.5,5,10,17.5,25 \% w / v$ concentrations, these were added at $6 \mathrm{~mL}$ and $39 \mathrm{~mL}$ per Petri dish, for redroot pigweed and maize, respectively. The treatments were replicated thrice according to a completely randomised design and the bioassay with redroot pigweed was repeated twice. All Petri dishes in bioassays were placed in a growth chamber at dark, with temperature cycles of $12 \mathrm{~h}$ at $20^{\circ} \mathrm{C}$ and $12 \mathrm{~h}$ at $30^{\circ} \mathrm{C}$ for maize and $24 \mathrm{~h}$ at $20^{\circ} \mathrm{C}$ forredroot pigweed. Germinated seeds were counted after 10 days and six representative seedlings per Petri dish were chosen to determine the radicle and hypocotyl lengths. Germination, radicle and hypocotyl length data for each species were converted to percentage relative to untreated control [42].

\subsection{Experiment 2: Pot Culture Bioassays}

Plastic pots ( $55 \mathrm{~mm} \varnothing_{\max }, 37 \mathrm{~mm} \varnothing_{\min }, 50 \mathrm{~mm}$ depth, 3 holes in bottom) were previously closed, putting discs $(37 \mathrm{~mm} \varnothing)$ of filter paper (specific weight $90 \mathrm{~g} \mathrm{~m}^{-2}$ ) in the bottom and then were filled with $65 \mathrm{~mL}$ (corresponding to $80.6 \mathrm{~g}$ ) of quartz sand (inert substrate, $0.2-2 \mathrm{~mm}$ mesh size, $1.24 \mathrm{~g} \mathrm{~mL}^{-1}$ bulk

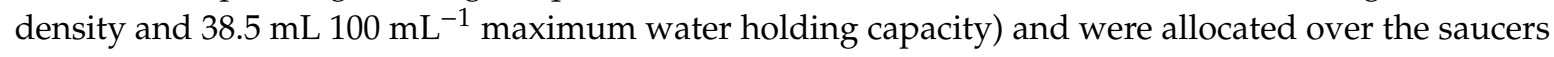
(80 $\mathrm{mm} \varnothing$ and $20 \mathrm{~mm}$ depth). Four seeds of maize and 30 seeds of redroot pigweed were sown per pot. These pots were kept in glasshouse (minimum/maximum air temperature: $10^{\circ} \mathrm{C} / 25^{\circ} \mathrm{C}$; light/dark period: $13 / 11 \mathrm{~h}$ ) in completely randomised design with three replications. Pots were subirrigated to maximum water holding capacity with 6-extract concentrations $(0,2.5,5.0,7.5,10.0$ and $12.5 \%$ $w / v)$ using saucers as the "subirrigation system". After emergence, seedlings were counted and then thinned to 5 (redroot pigweed) and 3 (maize) plants per pot. Water content was daily adjusted to maximum water holding capacity by subirrigation with a nutrient solution containing all necessary macro and micro-elements (Flory $9^{\circledR}$, Agrimport; 1 g c.f. $\mathrm{L}^{-1}+$ urea $0.1 \mathrm{~g}$ c.f. $\mathrm{L}^{-1}+$ Sequestrene $^{\circledR} \mathrm{NK}$ $138 \mathrm{Fe}$, Ciba-Geigy $0.04 \mathrm{~g}$ c.f. $\mathrm{L}^{-1}$ ). Three weeks after emergence, plants were harvested and the above ground fresh and dry weight per pot was recorded. Data of seedling emergence, fresh and dry weight were expressed as percentage of untreated control [42].

\subsection{Statistical Analysis}

Bioassays data were subjected to non-linear regression analyses by using the log-logistic model proposed by Streibig et al. [43]:

$$
Y=C+\frac{D-C}{1+\exp \{b[\log (X)-\log (a)]\}}
$$

where $Y$ is the response (i.e., percentage of seed germination, radicle or meso/hypocotyl length of seedlings, seedling emergence and fresh or dry above-ground biomass of plants) of the test seed or plant as a function of the extract concentration $X, D$ is the upper asymptote (response of the untreated control), $C$ is the lower asymptote (response at extremely high concentration), $a$ is the concentration 
that give a response half way between upper and lower asymptotes and $b$ is the slope around the inflection point.

In some cases, growth stimulation was observed at low concentration doses, hence, the following peaked model was used [44]:

$$
Y=C+\frac{D-C+f X}{1+\exp \{b[\log (X)-\log (a)]\}}
$$

where, $f$ is the parameter for stimulation.

Fitted equations were used to calculate the extract solution concentration required to give $10 \%$, $50 \%$ and $90 \%$ reduction of the control value in terms of seed germination, radicle or meso/hypocotyl length of seedlings and plant biomass, i.e., $\mathrm{EC}_{10}, \mathrm{EC}_{50}$ and $\mathrm{EC}_{90}$ (effective concentration) [45]. In the case of plant biomass, EC values were generated by using both the fresh and dry weight data. As the fresh weight and dry weight data showed a similar trend, only $\mathrm{EC}_{10}, \mathrm{EC}_{50}$ and $\mathrm{EC}_{90}$ values, on the basis of the dry weight data, were included.

The assumption that dose-response curves could be fitted to the data was assessed by an F-test for lack-of-fit comparing the residual sum of squares of an analysis of variance and the non-linear regression [46].

The models were fitted to the experimental data using the EXCEL ${ }^{\circledR}$ Add-in macro BIOASSAY97 [47].

\section{Results and Discussion}

\subsection{Qualitative Composition of the Extract}

The aqueous extract of mugwort was qualitatively examined (using chromatographic and spectroscopic methods) for the presence of bioactive compounds as detailed in the Materials and Methods section. The preliminary investigation of the ${ }^{1} \mathrm{H}-\mathrm{NMR}$ spectrum (Figure 1a) of the lyophilized aqueous extract showed the presence of different signals due to sugars (monosaccharides, oligosaccharides or polysaccharides) protons. The presence of high ( $>3500 \mathrm{Da}$ ) molecular weight compounds was confirmed by spectroscopic analysis of the dialysis tubes content after dyalization of the aqueous extract in tubes with exclusion limits of $3500 \mathrm{Da}$. In fact, the ${ }^{1} \mathrm{H}-\mathrm{NMR}$ spectrum (Figure 1b) of its lyophilizate showed the presence of the typical signals of carbohydrates as well as the signals of methyl groups probably due to the presence of some amino- and deoxy-sugars [48,49].

The presence of lipophilic low molecular weight metabolites, belonging to different classes of natural compounds, was ascertained by carrying out successive extractions with organic solvents of increasing polarity. The ${ }^{1} \mathrm{H}-\mathrm{NMR}$ analysis (Figure $1 \mathrm{c}-\mathrm{e}$ ) of the organic extracts obtained revealed the presence of signals due to aromatic double bonds, methoxy groups, methylenic protons and methyl groups. These signals are significant for the presence of different flavonoids and terpenoids which are already reported as phytochemical constituents of mugwort [50].

The aqueous extract was also acidified at $\mathrm{pH} 2$ and a brown oily residue $(147.9 \mathrm{mg})$ was obtained in good yield compared to the organic extracts obtained at $\mathrm{pH} 7$ (Table 1).

Table 1. Yield (mg) of organic extracts obtained from the aqueous stock extract $(40 \mathrm{~mL})$ of mugwort plants using solvents with different polarity and different $\mathrm{pH}$ values.

\begin{tabular}{ccccc}
\hline pH Value & \multicolumn{4}{c}{ Organic Solvent } \\
\hline & $n$-hexane & $\mathrm{CH}_{2} \mathrm{Cl}_{2}$ & EtOAc & $n$-butanol \\
7 & $1.7 \mathrm{mg}$ & $17.2 \mathrm{mg}$ & $23.5 \mathrm{mg}$ & $20.3 \mathrm{mg}$ \\
2 & n.d. ${ }^{1}$ & n.d. & $147.9 \mathrm{mg}$ & n.d. \\
\hline \multicolumn{4}{c}{${ }^{1}$ n.d. $=$ not determined. }
\end{tabular}



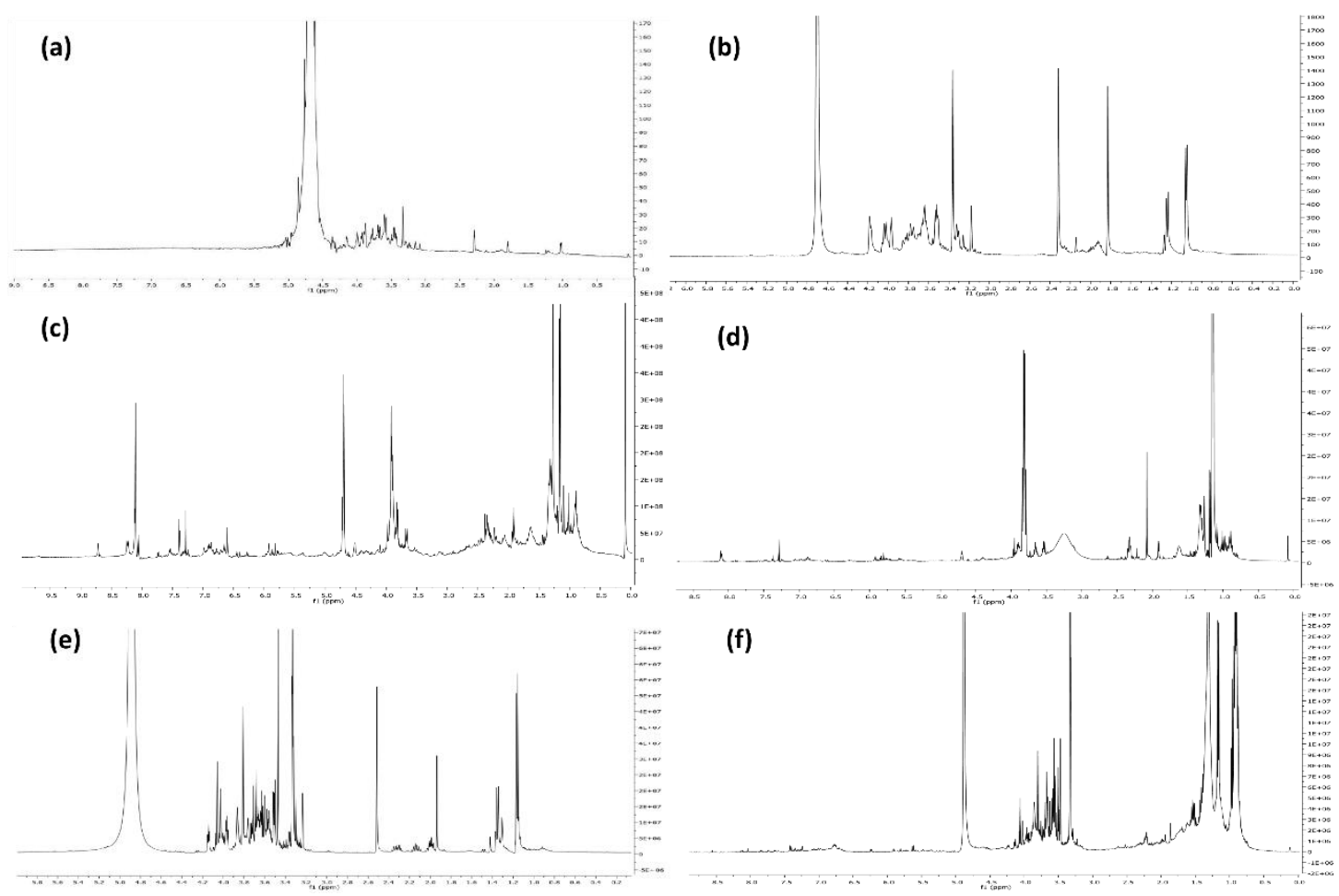

Figure 1. (a) ${ }^{1} \mathrm{H}$ NMR spectrum of the aqueous stock extract recorded at $400 \mathrm{MHz}$ in $\mathrm{D}_{2} \mathrm{O}$; (b) ${ }^{1} \mathrm{H}$ NMR spectrum of the dialysis tubes content after dyalization of the aqueous stock extract recorded at $400 \mathrm{MHz}$ in $\mathrm{D}_{2} \mathrm{O}$; (c) ${ }^{1} \mathrm{H}$ NMR spectrum of the $\mathrm{CH}_{2} \mathrm{Cl}_{2}$ organic extract recorded at $400 \mathrm{MHz}$ in $\mathrm{CDCl}_{3} ;(\mathbf{d}){ }^{1} \mathrm{H} \mathrm{NMR}$ spectrum of the EtOAc organic extract recorded at $400 \mathrm{MHz}$ in $\mathrm{CDCl}_{3}$; (e) ${ }^{1} \mathrm{H} \mathrm{NMR}$ spectrum of the $n$-butanol organic extract recorded at $400 \mathrm{MHz}$ in $\mathrm{CD}_{3} \mathrm{OD}$; (f) ${ }^{1} \mathrm{H}$ NMR spectrum of the EtOAc organic extract obtained acidifying the stock solution at $\mathrm{pH} 2$ recorded at $400 \mathrm{MHz}$ in $\mathrm{CD}_{3} \mathrm{OD}$.

The acid extract showed the presence of several organic acids when analyzed by TLC and NMR (Figure 1f). This result is in agreement with the literature data which showed that chlorogenic, caffeic and dicaffeoylquinic acids are the major low molecular weight constituents produced by mugwort [51].

Thus, the qualitative chemical analysis of the aqueous extract of mugwort showed that beside the large number of polysaccharides also good amount of organic acids and interesting terpenoids and flavonoids are contained. However, further analyses are needed in order to identify the compounds contained in the extract responsible for its phytotoxic activity.

\subsection{Exp.1: Effects of Extract on Seed Germination, Radicle and Hypocotyl Lengths of Seedling in Maize and Redroot Pigweed}

In Petri dish bioassays, the aqueous extract of aerial biomass of mugwort inhibited the seed germination of redroot pigweed but not that of maize (Figure $2 \mathrm{a}$ ). The $\mathrm{EC}_{10}, \mathrm{EC}_{50}$ and $\mathrm{EC}_{90}$ values were estimated only from the dose-response curves of redroot pigweed, while, EC values were not estimable in maize, since the extract did not influence its seed germination (Figure 2a and Table 2). In particular, $\mathrm{EC}_{90}$ values for the germination of redroot pigweed in the two repeated bioassays were $6.1 \%$ and $8.1 \% w / v$ of aqueous extract, that means as these concentrations of mugwort extract were able to reduce of $90 \%$ the germination of redroot pigweed compared to untreated control. 
Table 2. $\mathrm{EC}_{10}, \mathrm{EC}_{50}$ and $\mathrm{EC}_{90}$ values $(\%$ w/v) of aqueous extracts of mugwort, on seed germination, radicle and meso/hypocotyl length of maize and redroot pigweed (A. retroflexus) (1 and 2 mean the two repeated bioassays) seedlings (standard errors and confidential intervals are in parentheses; n.e.: not evaluable).

\begin{tabular}{|c|c|c|c|c|c|c|c|c|c|c|c|c|c|c|c|c|c|c|}
\hline \multirow{2}{*}{ Species } & \multicolumn{6}{|c|}{ Germination (\%) } & \multicolumn{6}{|c|}{ Radicle Lenght } & \multicolumn{6}{|c|}{ Meso/Hypocotyl Length } \\
\hline & \multicolumn{2}{|c|}{$\mathrm{EC}_{\mathbf{1 0}}$} & \multicolumn{2}{|c|}{$\mathrm{EC}_{50}$} & \multicolumn{2}{|c|}{$\mathrm{EC}_{90}$} & \multicolumn{2}{|c|}{$\mathrm{EC}_{10}$} & \multicolumn{2}{|c|}{$\mathrm{EC}_{50}$} & \multicolumn{2}{|c|}{$\mathrm{EC}_{90}$} & \multicolumn{2}{|r|}{$\mathrm{EC}_{10}$} & \multicolumn{2}{|r|}{$\mathrm{EC}_{50}$} & \multicolumn{2}{|r|}{$\mathrm{EC}_{90}$} \\
\hline A. retroflexus_1 & 1.2 & $(0.06)$ & 3.1 & $(0.06)$ & 8.1 & $(0.37)$ & 2.9 & $(0.03)$ & 4.2 & $(0.02)$ & 6.2 & $(0.03)$ & 4.4 & $(4.00-4.55)$ & 4.8 & $(4.58-4.84)$ & 5.7 & $(5.45-6.10)$ \\
\hline A. retroflexus_2 & 1.1 & $(0.06)$ & 2.6 & $(0.04)$ & 6.1 & $(0.24)$ & 2.5 & $(0.001)$ & 2.8 & $(0.02)$ & 3.2 & $(0.04)$ & 3.5 & $(1.77-4.70)$ & 3.6 & $(1.78-4.70)$ & 3.8 & $(1.71-4.70)$ \\
\hline Maize & & $>25$ & & $>25$ & & $>25$ & 17.7 & (n.e.) & & $>25$ & & $>25$ & 18.8 & $(3.50-31.56)$ & & $>25$ & & $>25$ \\
\hline
\end{tabular}



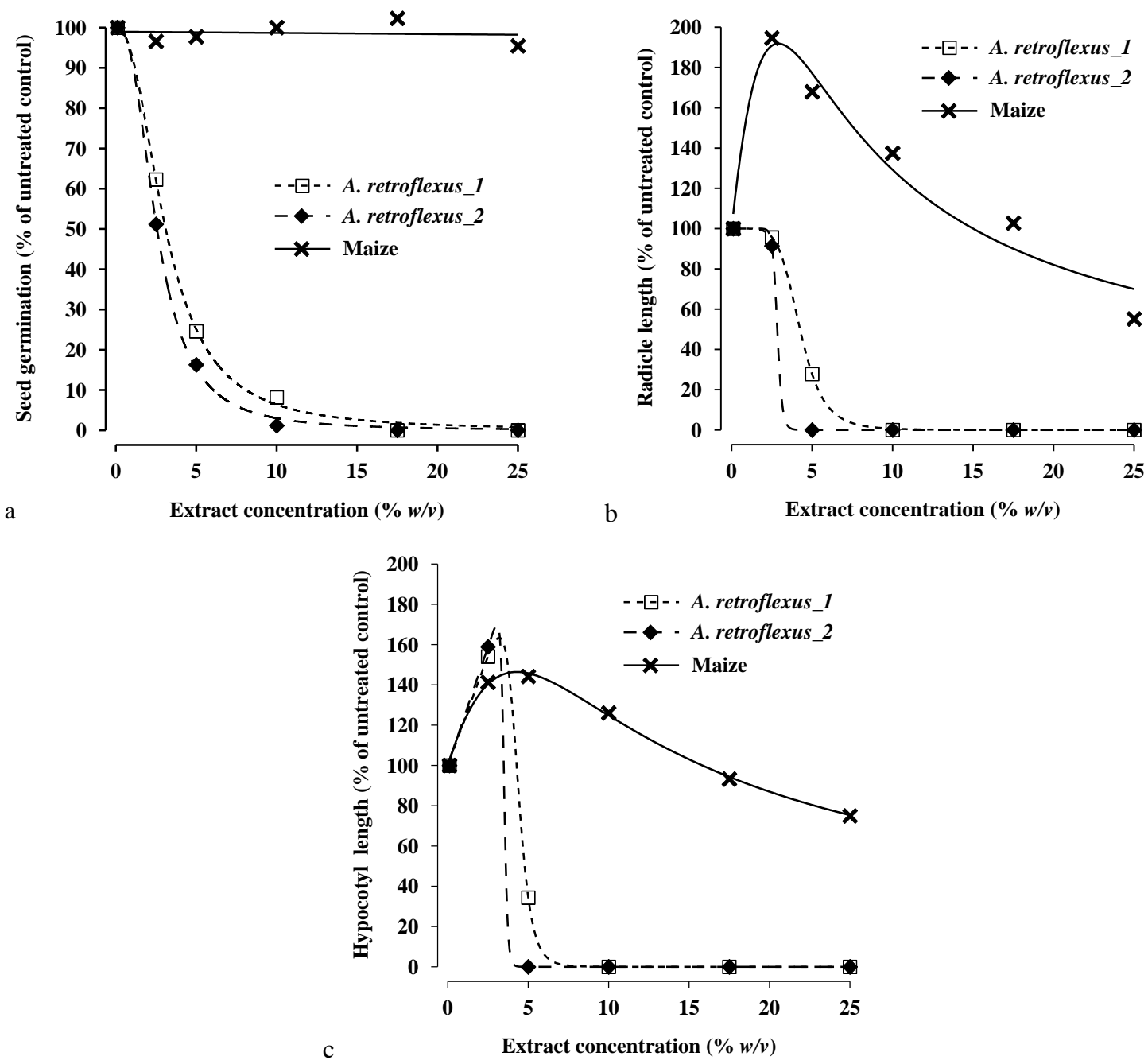

Figure 2. Effects of aerial biomass aqueous extracts of mugwort on seed germination (graphic a), radicle length (graphic $\mathbf{b}$ ) and mesocotyl/hypocotyl length (graphic $\mathbf{c}$ ) of maize and redroot pigweed (A. retroflexus) seedlings (1 and 2 mean the two repeated bioassays). Symbols show observed data in the experiment 1 , lines show fitted curves according to models 1 and 2.

Radicle and hypocotyl length of redroot pigweed were severely affected by mugwort extract that at the concentrations of $10 \% w / v$ and over, inhibited completely their growth (Figure $2 \mathrm{~b}, \mathrm{c}$ ). In particular, $\mathrm{EC}_{10}, \mathrm{EC}_{50}$ and $\mathrm{EC}_{90}$ values were similar between radicle and hypocotyl length, ranging from $2.5 \%$ to $4.4 \%$, from $2.8 \%$ to $4.8 \%$ and from $3.2 \%$ to $6.2 \% w / v$, respectively, in the two repeated bioassays (Table 1). Inhibitory effect against radicle length of redroot pigweed was observed also by Scavo et al. [52], studying the differences in the allelopathic activity of three Cynara cardunculus L. botanical varieties (globe artichoke, cultivated and wild cardoon) leaf aqueous extracts on the seedling growth of redroot pigweed. Radicle and mesocotyl of maize showed a low growth inhibition only at the highest concentration of mugwort extract, while at the lowest extract concentrations, radicle and mesocotyl were highly and significantly stimulated to growth. Stimulation parameters were: $f=75.1$ $(p=0.018)$ for radicle length; $f=26.2(p=0.008)$ for mesocotyl length (Figure $1 \mathrm{~b}, \mathrm{c}$ ).

In particular, the extract concentrations from $7.5 \%$ to $10 \% w / v$, can be defined as the optimal concentration range since it is able to inhibit the germination and growth of redroot pigweed, without to affect germination of maize, or rather, stimulating its radicle and mesocotyl growth. This stimulation phenomenon, known as hormesis, has been observed both with herbicides and allelopathic extracts $[18,41,53]$ and also with extracts of mugwort in potato cultivation [54]. From an 
agricultural point of view, it could be exploited to increase the crop production and quality as done by plant biostimulants [55].

Recently, plant extracts were considered as plant biostimulants, according the following definition: "A plant biostimulant is any substance or microorganism applied to plants with the aim to enhance nutrition efficiency, abiotic stress tolerance and/or crop quality traits, regardless of its nutrients content." Indeed, in this definition, a substance may be either a single chemical compound or a group of compounds having a well-established biological origin, e.g., plant extracts, but not necessarily a fully characterized composition [55]. In this context, a plant extract with potential herbicidal activity against weeds and biostimulant action on the crops, like mugwort extract, could be the ideal solution in an integrated weed management program, in order to suppress weeds, increasing competitive ability of crops.

\subsection{Exp.2: Effects of Extract on Seedlings Emergence and Plant Growth in Maize Andredroot Pigweed}

In pot culture bioassays, the data confirmed the results obtained in Petri dish bioassays. In particular, the aqueous extract of aerial biomass of mugwort inhibited the seedlings emergence of redroot pigweed but not that of maize (Figure 3a). The $\mathrm{EC}_{10}, \mathrm{EC}_{50}$ and $\mathrm{EC}_{90}$ values were estimated only from the dose-response curves of redroot pigweed, while, EC values were not estimated in maize, since the extract did not influence its seedlings emergence (Figure 3a and Table 3).

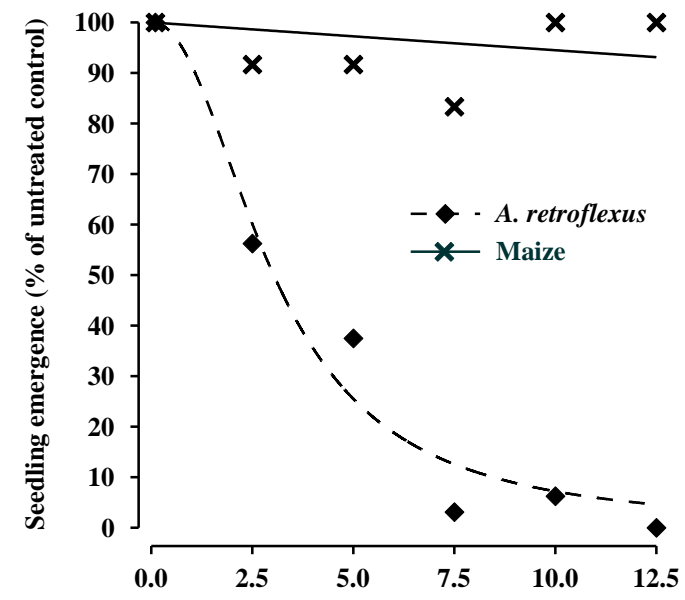

a

Extract concentration $(\% w / v)$

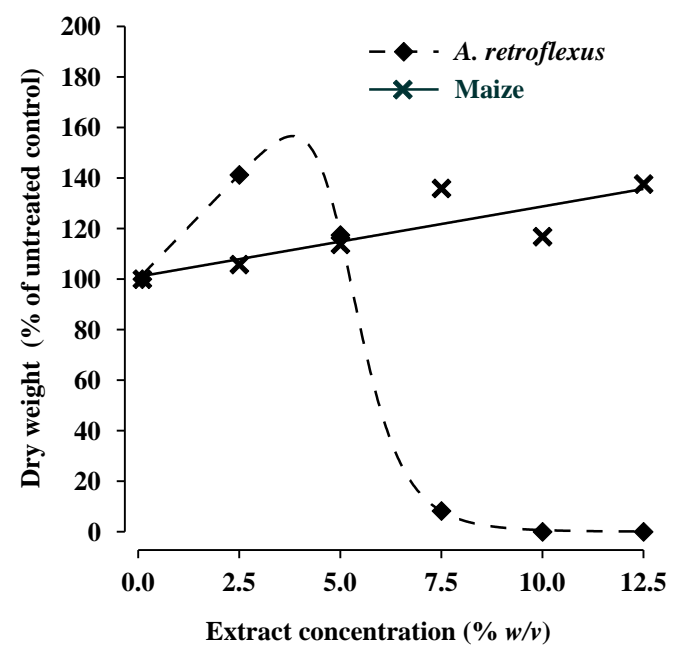

Figure 3. Emergence (graphic a) and dry weight (graphic b) of maize and A. retroflexus plants as affected by aerial biomass extract of mugwort. Symbols show observed data in the experiment 2 , lines show fitted curves according to the models 1 and 2.

Table 3. $\mathrm{EC}_{10}, \mathrm{EC}_{50}$ and $\mathrm{EC}_{90}$ values ( $\left.\% w / v\right)$ of aerial biomass aqueous extracts of mugwort on seedling emergence and plant dry weight of maize and redroot pigweed (A. retroflexus) (standard errors and confidential intervals are in parentheses).

\begin{tabular}{|c|c|c|c|c|c|c|c|c|c|}
\hline \multirow{2}{*}{ Species } & \multicolumn{3}{|c|}{ Seedling Emergence } & \multicolumn{6}{|c|}{ Plant Dry Weight } \\
\hline & $\mathrm{EC}_{10}$ & $\mathrm{EC}_{50}$ & $\mathrm{EC}_{90}$ & & $\mathrm{EC}_{10}$ & & $\mathrm{EC}_{50}$ & & $\mathrm{EC}_{90}$ \\
\hline A. retroflexus & $1.1 \quad(0.35)$ & $3.0 \quad(0.39)$ & $8.5 \quad(1.90)$ & 5.4 & $(5.33-5.42)$ & 6.0 & $(5.89-6.04)$ & 7.3 & $(7.52-7.12)$ \\
\hline Maize & $>12.5$ & $>12.5$ & $>12.5$ & & $>12.5$ & & $>12.5$ & & $>12.5$ \\
\hline
\end{tabular}

In particular, EC values for seedlings emergence of redroot pigweed were comparable with those of seed germination obtained in the experiment 1 , confirming the inhibitory effects of the extract, also in pot conditions with the presence of a substrate. Indeed, in pot bioassays, the extract inhibited seed germination at the same concentration levels of the Petri disc bioassays, so affected the seedlings emergence of redroot pigweed (Figure 3a). These evidences are promising from a practical 
point of view, for the application of the extract as a pre-emergence bioherbicide, directly in the field. In this case, the behaviour of allelochemicals in the soil is fundamental for the determination of their phytotoxic effects, particularly the adsorption-desorption balance, which influences the concentration of allelochemicals in soil water [56]. The soil can reduce the bioavailability of the extract and so its phytotoxic effects, as already observed by Pannacci et al. [17], that found a bioavailability of $50 \%$, for the aqueous extract of mugwort in a sandy loam soil. The EC levels of extract, just as determined in this pot experiment using an inert substrate, can be adapted to different soil types by knowing the bioavailability of the extract in each soil [41,57]. In this way, the EC levels of mugwort aqueous extract reported in Table 3 could be adapted to the sandy loam soil above mentioned, reduplicating their values, if the extract would be applied in the field as a pre-emergence bioherbicide to control redroot pigweed in maize crop.

The effect of the increasing of mugwort extract concentration on plant growth in maize and redroot pigweed at three weeks after emergence were reported in Figure $3 \mathrm{~b}$. In particular, the dry weight of maize plants increased linearly $\left(y=2.78 x+100.94, R^{2}=0.71\right)$ with the increasing of extract concentration, confirming the stimulatory effects of the extract on maize growth, as already observed in Petri dish experiment on radicle and hypocotyl length of maize seedlings (Figure 2b,c and Figure $3 b$ ). As in the case of seedlings emergence, the EC values were estimated only from the dose-response curves of redroot pigweed, while, EC values were not estimated in maize due to stimulation effect of the extract (Table 3). The dry biomass of redroot pigweed was completely inhibited at the extract concentrations higher than $7.5 \% w / v$ (Figure $3 \mathrm{~b}$ ), as shown by the $\mathrm{ED}_{90}$ value of $7.3 \% w / v$ (Table 3). These results were in line with those of the experiment 1 , confirming that the extract concentrations from $7.5 \% w / v$ to $10 \% w / v$, were the optimal concentration range to apply the extract as a pre-emergence bioherbicide. Indeed, this range of extract concentrations was able to inhibit the emergence and biomass growth of redroot pigweed plants, without to affect emergence of maize and stimulating its biomass growth. The application of mugwort aqueous extract as a potential pre-emergence bioherbicide were also tested by Pannacci et al. [17] in two years' field experiments in winter wheat, where, the same extract at the concentration of $20 \% w / v$, gave a $50 \%$ efficacy to reduce the emergence of Lolium multiflorum Lam. plants, showing a good selectivity to the crop. However, further research is needed to increase the data on the efficacy of mugwort extract against other weeds and on its selectivity to other crops. For this reason, in the experiment 1, the mugwort extract was also tested on green bean (Phaseolus vulgaris L., cv. Blue lake s7) obtaining results comparable with those of maize, in terms of seed germination, radicle and mesocotyl lengths (data not shown). Furthermore, Kadioglu and Yusuf [38] found that methanol extract of mugwort's plants inhibited the germination of several weeds, such as Abutilon theophrast $i$ Medik, A. retroflexus L., Avena sterilis L., Rumex crispus L. and Lolium perenne L., confirming our results and showing so a good allelopathic activity of the extract to control both grass and broadleaves weeds, regardless seeds size.

\section{Conclusions}

The qualitative chemical analysis of the aqueous extract of mugwort showed the presence of several bioactive compounds with allelopathic activity, such as polysaccharides, organic acids, flavonoids and terpenoids.

In Petri dish bioassays, the aqueous extract of aerial biomass of mugwort inhibited the seed germination of redroot pigweed, but not that of maize. Radicle and hypocotyl length of redroot pigweed were severely affected by mugwort extract that at the concentrations of $10 \% w / v$ and over, inhibited completely their growth, while radicle and mesocotyl of maize were highly and significantly stimulated to growth.

In pot culture bioassays, the aqueous extract of mugwort inhibited the seedlings emergence and the subsequent plant growth of redroot pigweed, while maize was not affected in seedlings emergence with a stimulation of plant biomass. 
The extract concentrations from $7.5 \%$ to $10 \% w / v$, were found to be the optimal concentration range since it is able to inhibit the germination and growth of redroot pigweed, without to affect germination of maize, or rather, stimulating its radicle, mesocotyl and plant's growth.

These evidences are promising from a practical point of view, for the application of the extract as a bioherbicide in pre-emergence, directly in the field. Indeed, a plant extract with potential herbicidal activity against weeds and biostimulant action on the crops, could be the ideal solution in an integrated weed management program, in order to suppress weeds, increasing competitive ability of crops.

However, further analyses are needed in order to identify the compounds contained in the extract responsible for its phytotoxic activity, understanding the modes of action involved in the inhibition of seed germination and seedlings growth of weeds. Doing that, it will be possible to improve the use of the extract as a pre-emergence bioherbicide or to open the way for the discovery of new herbicides with new modes of action. Furthermore, for an optimal use of allelopathic potential of mugwort's extract, under field conditions, the influence of environmental factors could be a limitation and needs to be more investigated in the future, as well as, the phytotoxic effects of the extract against other weeds and crops, in order to extend the potential application as bioherbicide to control more weeds in different crops and environmental conditions.

Author Contributions: Conceptualization, E.P.; data curation, E.P. and M.M.; formal analysis, E.P. and M.M.; methodology, E.P. and M.M.; writing-original draft preparation, E.P.; writing-review and editing, E.P., M.M., M.F. and F.T. All authors have read and agreed to the published version of the manuscript.

Funding: This research received no external funding.

Acknowledgments: The authors would like to acknowledge Locchi Silvano (Dept. of Agricultural, Food and Environmental Sciences, University of Perugia) for technical assistance in the bioassays experiments.

Conflicts of Interest: The authors declare no conflict of interest.

\section{References}

1. FAOSTAT-Crops Data. 2020. Available online: http://www.fao.org/faostat/en/\#data/QC (accessed on 9 December 2020).

2. World Data Atlas, World and Regional Statistics, National Data, Maps, Rankings: Maize Production Quantity. Knoema. 2020. Available online: https://knoema.com/atlas/topics/Agriculture/Crops-Production-Quantitytonnes/Maize-production (accessed on 22 November 2020).

3. Mhlanga, B.; Chauhan, B.S.; Thierfelder, C. Weed management in maize using crop competition: A review. Crop Prot. 2016, 88, 28-36. [CrossRef]

4. European Commission. Cereals Market Situation Committee for the Common Organisation of Agricultural Markets, 29 October 2020. 2020. Available online: https://circabc.europa.eu/sd/a/df2b1c9e-56be-456e-b1da4bc27e13de1a/cereals-balance-sheets-2017-18-and-forecast-2018-19.pdf (accessed on 22 November 2020).

5. Rouf Shah, T.; Prasad, K.; Kumar, P. Maize-A potential source of human nutrition and health: A review. Cogent Food Agric. 2016, 2, 1166995. [CrossRef]

6. Pannacci, E. Optimization of foramsulfuron doses for post-emergence weed control in maize (Zea mays L.). Span. J. Agric. Res. 2016, 14, e1005. [CrossRef]

7. Gianessi, L.; Williams, A. High Maize Yields in Europe Depend on Herbicides. International Pesticide Benefits Case Study No. 14. Crop Protection Research Institute, CropLife Foundation. 2011. Available online: https://croplife.org/case-study/high-maize-yields-in-europe-depend-on-herbicides/ (accessed on 20 November 2020).

8. Melander, B.; Rasmussen, I.A.; Barbéri, P. Integrating physical and cultural methods of weed control e examples from European research. Weed Sci. 2005, 53, 369-381. [CrossRef]

9. Upadhyaya, M.K.; Blackshaw, R.E. Non-Chemical Weed Management. Principles, Concepts and Technology; CABI Press: Oxfordshire, UK, 2007; p. 239.

10. Pannacci, E.; Tei, F. Effects of mechanical and chemical methods on weed control, weed seed rain and crop yield in maize, sunflower and soyabean. Crop Prot. 2014, 64, 51-59. [CrossRef]

11. Cimmino, A.; Masi, M.; Evidente, M.; Superchi, S.; Evidente, A. Fungal phytotoxins with potential herbicidal activity: Chemical and biological characterization. Nat. Prod. Rep. 2015, 32, 1629-1653. [CrossRef] 
12. Novakoski, A.D.S.; Coelho, É.M.P.; Ravagnani, G.T.; Da Costa, A.C.P.R.; Rocha, S.A.; Zucareli, V.; Lopes, A.D. Allelopathic Potential of Plant Aqueous Mixtures on Euphorbia heterophylla. Agriculture 2020, 10, 449. [CrossRef]

13. Rice, E.L. Allelopathy, 2nd ed.; Academic Press: New York, NY, USA, 1984; p. 422.

14. Weston, L.A.; Inderjit, S. Allelopathy: A potential tool in the development of strategies for biorational weed management. In Non-Chemical Weed Management-Principles, Concepts and Technology; Upadhyaya, M.K., Blackshaw, R.E., Eds.; CABI Press: Oxfordshire, UK, 2007; pp. 65-76.

15. Findura, P.; Hara, P.; Szparaga, A.; Kocira, S.; Czerwińska, E.; Bartoš, P.; Nowak, J.; Treder, K. Evaluation of the Effects of Allelopathic Aqueous Plant Extracts, as Potential Preparations for Seed Dressing, on the Modulation of Cauliflower Seed Germination. Agriculture 2020, 10, 122. [CrossRef]

16. Ehlert, K.A.; Mangold, J.M.; Engel, R.E. Integrating the herbicide imazapic and the fungal pathogen Pyrenophora semeniperda to control Bromus tectorum. Weed Res. 2014, 54, 418-424. [CrossRef]

17. Pannacci, E.; Pettorossi, D.; Regni, L.; Tei, F. Allelopathic potential of mugwort (Artemisia vulgaris L.) to control the Italian ryegrass (Lolium multiflorum Lam.) in winter wheat. Allelopath. J. 2015, 36, 257-272.

18. Pannacci, E.; Pettorossi, D.; Tei, F. Phytotoxic effects of aqueous extracts of sunflower on seed germination and growth of Sinapis alba L., Triticum aestivum L. and Lolium multiflorum Lam. Allelopath. J. 2013, 32, $23-36$.

19. Scavo, A.; Mauromicale, G. Integrated Weed Management in Herbaceous Field Crops. Agronomy 2020, 10, 466. [CrossRef]

20. Soltys, D.; Krasuska, U.; Bogatek, R.; Gniazdowska, A. Allelochemicals as Bioherbicides—Present and Perspectives; InTech: London, UK, 2013; Chapter 20; pp. 517-542. Available online: http://cdn.intechopen.com/pdfs-wm/ 44466.pdf (accessed on 20 November 2020).

21. Cai, X.; Gu, M. Bioherbicides in organic horticulture. Horticulturae 2016, 2, 3. [CrossRef]

22. Bhadoria, P.B.S. Allelopathy: A natural way towards weed management. Am. J. Exp. Agric. 2011, 1, 7-20. [CrossRef]

23. Ferreira, J.F.S.; Janick, J. Allelopathic Plants. XVI. Artemisia Species. Allelopath. J. 2004, 14, 167-176.

24. Weston, L.A.; Barney, J.N.; DiTommaso, A. A review of the biology and ecology of three invasive perennials in New York State: Japanese knotweed (Polygonum cuspidatum), mugwort (Artemisia vulgaris) and pale swallow-wort (Vincetoxicum rossicum). Plant Soil 2005, 277, 53-69. [CrossRef]

25. Duke, J.A.; Bogenshutz-Godwin, M.J.; du Cellier, M.J.; Duke, P.A. Handbook of Medicinal Herbs, 2nd ed.; CRC Press: Boca Raton, FL, USA, 2002; p. 870.

26. Marcinkeviciene, A.; Zita Kriauciuniene, Z.; Velicka, R.; Kosteckas, R.; Fujii, Y. Allelopathic effect of Artemisia vulgaris on winter wheat and winter oilseed rape. Fresen. Environ. Bull. 2018, 27, 727-732.

27. Weston, L.A.; Duke, S.O. Weed and crop allelopathy. Crit. Rev. Plant Sci. 2003, 22, 367-389. [CrossRef]

28. Barney, J.N.; Hay, A.G.; Weston, L.A. Isolation and characterization of allelopathic volatiles from mugwort (Artemisia vulgaris). J. Chem. Ecol. 2005, 31, 247-265. [CrossRef]

29. Harker, K.N.; O'Donovan, J.T. Recent weed control, weed management, and integrated weed management. Weed Technol. 2013, 27, 1-11. [CrossRef]

30. Sheibany, K.; Baghestani, M.A.; Atri, A. Competitive effects of redroot pigweed (Amaranthus retroflexus) on growth indices and yield of corn. Weed Biol. Manag. 2009, 9, 152-159. [CrossRef]

31. Kenzevic, S.Z.; Weise, S.F.; Swanton, C.J. Interference of redroot pigweed (Amaranthus retroflexus) in corn (Zea mays L.). Weed Sci. 1994, 42, 568-573. [CrossRef]

32. Bosnic, A.C.; Swanton, C.J. Influence of barnyard grass (Echinochloa crus-galli) time of emergence and density on corn (Zea mays). Weed Sci. 1997, 45, 276-282. [CrossRef]

33. Heap, I. The International Survey of Herbicide Resistant Weeds. 2020. Available online: http://www. weedscience.org (accessed on 10 November 2020).

34. Stepanovic, S.; Datta, A.; Neilson, B.; Bruening, C.; Shapiro, C.; Gogos, G.; Knezevic, S.Z. Effectiveness of flame weeding and cultivation for weed control in organic maize. Biol. Agric. Hortic. 2016, 32, 47-62. [CrossRef]

35. Cordeau, S.; Marion Triolet, M.; Wayman, S.; Steinberg, C.; Guillemin, J.-P. Bioherbicides: Dead in the water? A review of the existing products for integrated weed management. Crop Prot. 2016, 87, 44-49. [CrossRef]

36. Masi, M.; Pannacci, E.; Santoro, E.; Zermane, N.; Superchi, S.; Evidente, A. Stoechanones a and b, phytotoxic copaane sesquiterpenoids isolated from Lavandula stoechas with potential herbicidal activity against Amaranthus retroflexus. J. Nat. Prod. 2020, 83, 1658-1665. [CrossRef] [PubMed] 
37. Mei, L.; XingXiang, G.; ZongJun, G.; Qing, W. A primary study on allelopathy of Artemisia vulgaris. Acta Pratacult. Sin. 2010, 19, 114-119.

38. Kadioilu, I.; Yanar, Y. Allelopathic effects of plant extracts against seed germination of some weeds. Asian J. Plant Sci. 2004, 3, 472-475. [CrossRef]

39. Inderjit, S.; Foy, C.L. Nature of interference mechanism of mugwort (Artemisia vulgaris). Weed Technol. 1999, 13, 176-182. [CrossRef]

40. Meier, U. Growth Stages of Mono-and Dicotyledonous Plants. BBCH Monograph, 2nd ed.; Federal Biological Research Centre for Agriculture and Forestry: Berlin, Germany; Braunschweig, Germany, 2001; Available online: https://www.politicheagricole.it/flex/AppData/WebLive/Agrometeo/MIEPFY800/BBCHeng12001.pdf (accessed on 22 November 2020).

41. Pannacci, E.; Onofri, A.; Covarelli, G. Biological activity, availability and duration of phytotoxicity for imazamox in four different soils of central Italy. Weed Res. 2006, 46, 243-250. [CrossRef]

42. Abbott, W.S. A method of computing the effectiveness of an insecticide. J. Econ. Entomol. 1925, 18, $265-267$. [CrossRef]

43. Streibig, J.C.; Rudemo, M.; Jensen, J.E. Dose-response curves and statistical models. In Herbicide Bioassay; Streibig, J.C., Kudsk, P., Eds.; CRC Press: Boca Raton, FL, USA, 1993; pp. $29-55$.

44. Brain, P.; Cousens, R. An Equation to Describe Dose Responses where there is Stimulation of Growth at Low Dose. Weed Res. 1989, 29, 93-96. [CrossRef]

45. Pestemer, W.; Günther, P. Growth inhibition of plants as a bioassay for herbicide analysis. Chem. Plant Prot. 1995, 11, 219-231.

46. Ritz, C.; Streibig, J.C. Bioassay Analysis using R. J. Stat. Softw. 2005, 12, 1-22. [CrossRef]

47. Onofri, A.; Pannacci, E. Spreadsheet tools for biometry classes in crop science programmes. Commun. Biometry Crop. Sci. 2014, 9, 3-13.

48. Pretsch, E.; Bühlmann, P.; Affolter, C. Structure Determination of Organic Compounds Tables of Spectral Data, 3rd ed.; Springer: Berlin, Germany, 2000; pp. 161-243.

49. Berger, S.; Braun, S. 200 and More Basic NMR Experiments: A Practical Course, 1st ed.; Wiley-VCH: Weinheim, Germany, 2004; p. 854.

50. Abiri, R.; Silva, A.L.M.; de Mesquita, L.S.S.; de Mesquita, J.W.C.; Atabaki, N.; de Almeida, E.B., Jr.; Shaharuddin, M.A.; Malik, S. Towards a better understanding of Artemisia vulgaris: Botany, phytochemistry, pharmacological and biotechnological potential. Food Res. Int. 2018, 109, 403-415. [CrossRef]

51. Corrêa-Ferreira, M.L.; Verdan, M.H.; dos Reis Lívero, F.A.; Galuppo, L.F.; Telles, J.E.Q.; Stefanello, M.É.A.; Acco, A.; de Oliveira Petkowicz, C.L. Inulin-type fructan and infusion of Artemisia vulgaris protect the liver against carbon tetrachloride-induced liver injury. Phytomedicine 2017, 24, 68-76. [CrossRef]

52. Scavo, A.; Pandino, G.; Restuccia, A.; Lombardo, S.; Pesce, G.R.; Mauromicale, G. Allelopathic potential of leaf aqueous extracts from Cynara cardunculus L. on the seedling growth of two cosmopolitan weed species. Ital. J. Agron. 2019, 14, 1373. [CrossRef]

53. Duke, S.O.; Cedergreen, N.; Velini, E.D.; Belz, R.G. Hormesis: Is it an important factor in herbicide use and allelopathy? Outlooks Pest Manag. 2006, 17, 29-33.

54. Findura, P.; Kocira, S.; Hara, P.; Pawłowska, A.; Szparaga, A.; Kangalov, P. Extracts from Artemisia vulgaris L. in Potato Cultivation-Preliminary Research on Biostimulating Effect. Agriculture 2020, 10, 356. [CrossRef]

55. Du Jardin, P. Plant biostimulants: Definition, concept, main categories and regulation. Sci. Hortic. 2015, 196, 3-14. [CrossRef]

56. Scavo, A.; Abbate, C.; Mauromicale, G. Plant allelochemicals: Agronomic, nutritional and ecological relevance in the soil system. Plant Soil 2019, 442, 23-48. [CrossRef]

57. Günther, P.; Rahman, A.; Pestemer, W. Quantitative bioassays for determining residues and availability to plants of sulphonylurea herbicides. Weed Res. 1989, 29, 141-146. [CrossRef]

Publisher's Note: MDPI stays neutral with regard to jurisdictional claims in published maps and institutional affiliations. 